\title{
PRODUTIVIDADE DE CEBOLA INFLUENCIADA PELA APLICAÇÃO DE MICRONUTRIENTES ${ }^{(1)}$
}

\author{
Claudinei Kurtz ${ }^{(2)}$ \& Paulo Roberto Ernani ${ }^{(3)}$
}

\begin{abstract}
RESUMO
A aplicação excessiva de fertilizantes, o uso de corretivos da acidez sem critérios técnicos adequados e o monocultivo são práticas comuns na região cebolicultora catarinense, $\mathrm{e}$ isso tem contribuído para o aparecimento de sintomas visuais de deficiências nutricionais, principalmente de micronutrientes. $O$ presente trabalho objetivou avaliar o efeito da aplicação de B, Zn e Mn na produtividade e na conservação de bulbos de cebola. Foram conduzidos três experimentos independentes, em campo, sendo um para cada nutriente, no município de Ituporanga, SC, de 2006 a 2009. Em cada experimento, os tratamentos consistiram de aplicações do micronutriente ao solo e de pulverizações foliares. As doses aplicadas ao solo variaram de 0 a $4 \mathrm{~kg} \mathrm{ha}^{-1}$ para $\mathrm{Zn}$, de 0 a $4,4 \mathrm{~kg} \mathrm{ha}^{-1}$ para $\mathrm{B}$ e de 0 a $15,6 \mathrm{~kg} \mathrm{ha}^{-1}$ para Mn. As pulverizações foliares, em número de seis a cada ano, foram realizadas a cada 14 dias, nas concentrações de $0,5 \%$ de sulfato de zinco, de 0,25 \% de ácido bórico e de 1,0 \% de sulfato de manganês. A aplicação de Zn ao solo aumentou a produtividade de bulbos nas três safras, cujos incrementos variaram de 10 a 14,5 \%. A dose de Zn que proporcionou a máxima produtividade de bulbos variou de $2,7 \mathrm{~kg} \mathrm{ha}^{-1}$, na safra 2006/2007, para uma produtividade de $22,3 \mathrm{t}$ ha $^{-1}$, até a quantidade estimada de $4,5 \mathrm{~kg} \mathrm{ha}^{-1}$, na safra 2008/2009, para produtividade de 35,6 t ha ${ }^{-1}$. A aplicação de Mn e de B, independentemente do modo de aplicação, $\mathrm{e}$ as pulverizações foliares com $\mathrm{Zn}$ não influenciaram a produtividade de cebola em nenhuma safra. A qualidade dos bulbos, avaliada por meio da ausência de deterioração durante 145 dias de armazenamento, não foi influenciada pela adição de Zn, B ou Mn. Assim, é importante aplicar Zn para a produção de bulbos de cebola em Cambissolos catarinenses, mesmo naqueles em que o teor desse nutriente no solo esteja acima do nível crítico considerado para os solos da região, provavelmente, em função da exigência da cultura.
\end{abstract}

Termos de indexação: zinco, boro, manganês, adubação foliar, Allium cepa.

(1) Parte da Dissertação de Mestrado do primeiro autor apresentada ao programa de Pós-Graduação em Manejo do Solo da Universidade do Estado de Santa Catarina - UDESC. Recebido para publicação em maio de 2009 e aprovado em novembro de 2009.

${ }^{(2)}$ Pesquisador da Empresa de Pesquisa Agropecuária e Extensão Rural do Estado de Santa Catarina - EPAGRI. Estrada Geral Lageado Águas Negras, Caixa Postal 281, CEP 88400-000 Ituporanga (SC). E-mail: kurtz@epagri.sc.gov.br

(3) Professor do Departamento de Solos, Universidade do Estado de Santa Catarina - UDESC. Av. Luiz de Camões 2090, CEP 88520000 Lages (SC). Pesquisador do CNPq. E-mail: prernani@cav.udesc.br 


\title{
SUMMARY: ONION YIELD INFLUENCED BY MICRONUTRIENT APPLICATION
}

\begin{abstract}
The excessive use of fertilizers and liming as well as monoculture is rather common in the onion-producing region of Santa Catarina State, Brazil. Such practices have resulted in visual symptoms of micronutrient deficiency, mainly of micronutrients. This study aimed to measure the effect of $B, Z n$ and $M n$ fertilizers on yield and quality of onion bulbs. Three individual trials, one for each nutrient, were carried out in the field, in Ituporanga, southern Brazil, from 2006 until 2009. In each experiment, treatments consisted of increasing rates of each micronutrient applied to the soil before planting and also of a single rate sprayed onto the leaves six times per season. Rates applied to the soil varied from 0 to $4 \mathrm{~kg} \mathrm{ha}^{-1}$ for $\mathrm{Zn}$, from 0 to $4.4 \mathrm{~kg} \mathrm{ha}^{-1}$ for B, and from 0 to $15.6 \mathrm{~kg} \mathrm{ha}^{-1}$ for Mn. The spray solutions contained zinc sulfate, boric acid and manganese sulfate, at concentrations of $0.5,0.25$ and $1.0 \%$, respectively. The application of Mn or B, regardless of the form, and $\mathrm{Zn}$ sprays, had no effect on onion yield in any growing season. The application of $Z n$ to the soil increased onion yield in all three years, by 10-14.5\%. Maximum yield was obtained with $\mathrm{Zn}$ rates of $2.7 \mathrm{~kg} \mathrm{ha}^{-1}$ in 2006/2007

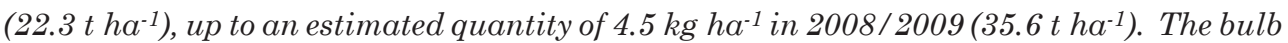
quality was not affected by micronutrient application ( $\mathrm{Mn}, \mathrm{B}$, or $\mathrm{Zn}$ ), regardless of the form. It is therefore important to apply Zn to the soil for onion production in the State of Santa Catarina, even where Zn concentration exceeds the critical level established for the region, which is probably due to the requirement of this crop.
\end{abstract}

Index terms: zinc, boron, manganese, foliar nutrition, Allium cepa.

\section{INTRODUÇÃO}

Entre as hortaliças, a cultura da cebola (Allium cepa L.) ocupa a terceira posição em importância econômica no Brasil. Santa Catarina é o maior produtor nacional, tendo colhido, na safra 2006/2007, 437 mil toneladas, em uma área cultivada de 20.800 ha, representando $35 \%$ do total produzido no País (Boing, 2007).

O incremento na produtividade da cebola, assim como a melhoria na sanidade e na qualidade dos bulbos, é influenciado pela nutrição das plantas. A adição excessiva de fertilizantes, principalmente de $\mathrm{N}, \mathrm{P} \mathrm{e} \mathrm{K}$, o uso indiscriminado de corretivos de acidez e o monocultivo são práticas comuns na região cebolicultora do Alto Vale do Itajaí, em Santa Catarina. Em decorrência disso, têm surgido desequilíbrios nutricionais em várias propriedades, que resultam no aparecimento de sintomas visuais de deficiência nas plantas, principalmente relacionados com $\mathrm{Mn}, \mathrm{B}$ e Zn (Epagri, 2000).

No solo, a maior parte da fração lábil dos micronutrientes encontra-se adsorvida às superfícies externas dos componentes orgânicos e inorgânicos, e apenas uma pequena proporção encontra-se na solução. As plantas, no entanto, somente os absorvem a partir da solução do solo, sobretudo na forma iônica. À medida que esses íons são absorvidos, há decréscimo da concentração da solução, que tende a ser reposta pelas diversas formas sólidas com as quais ela está em equilíbrio. A disponibilidade de micronutrientes às plantas é, portanto, alterada por vários fatores, destacando-se o $\mathrm{pH}$ do solo, material de origem, teor de matéria orgânica, interação entre alguns elementos químicos e intensidade de uso do solo e espécie vegetal. $\mathrm{O} \mathrm{pH}$ é $\mathrm{o}$ atributo de solo que normalmente mais altera a disponibilidade de micronutrientes. A elevação do $\mathrm{pH}$ diminui a disponibilidade de $\mathrm{Fe}, \mathrm{Cu}, \mathrm{Zn}, \mathrm{Mn}$ e B e aumenta a disponibilidade de Mo (Camargo et al., 1982; Bataglia, 1988; Ernani, 2008), principalmente por influenciar a adsorção específica e, para alguns nutrientes, por alterar as reações de precipitação (Krebs et al., 1998).

A resposta das culturas à adição de micronutrientes depende da disponibilidade de cada um deles no solo, das características genéticas das espécies e das condições de cultivo. A cebola é exigente em $\mathrm{Zn}, \mathrm{Mn}$, Cu e Mo (Tisdale et al., 1985; Mortvedt, 1991; Alloway, 2004), porém pouco suscetível à deficiência de B (Mortvedt, 1991). Em solos do Estado de São Paulo, a inclusão de B, de Zn e de Mo na adubação aumentou a produtividade de cebola em até $90 \%$ (Tanaka et al., 1970).

O B é o micronutriente mais estudado na cebola. Jayamohanrao (1974) verificou que a adição conjunta de $\mathrm{Cu}$ e de $\mathrm{B}$ melhorou a composição mineral dos bulbos, sobretudo no que se refere aos teores de $\mathrm{Ca}$, de $\mathrm{P}$ e de Fe. Ribeiro (1978) demonstrou a influência do $\mathrm{B}$ na qualidade e no armazenamento dos bulbos e verificou que os oriundos de plantas deficientes foram os que perderam mais peso, os que mais apodreceram e que tiveram maior alteração no sabor. Os bulbos 
deficientes em B apresentam as escamas mais externas endurecidas e enrugadas, e as mais internas, necrosadas (Calbo et al., 1986). Por sua vez, Peña et al. (1999) aplicaram 5,25 kg ha ${ }^{-1}$ de B e não obtiveram incremento na produtividade de peso dos bulbos fresco e secos. Em algumas situações, a aplicação de Zn ao solo tem aumentado a produtividade da cebola, e isso tem sido obtido com doses de $16 \mathrm{~kg} \mathrm{ha}^{-1}$ (Rafique et al., 2008), de $5 \mathrm{~kg} \mathrm{ha}^{-1}$ (Gupta et al., 1985), de $6 \mathrm{~kg} \mathrm{ha}^{-1}$ (Lal \& Maurya, 1983), de 2,52 kg ha-1 (Peña et al., 1999) ou com pulverizações foliares com $0,3 \mathrm{~g} \mathrm{~L}^{-1}$ (El-Tohamy et al., 2009). Asif et al. (1975) também verificaram que a adição de $\mathrm{Zn}$ ao solo aumentou a produtividade de matéria seca da parte aérea e de bulbos, porém observaram que o aumento de doses de $\mathrm{P}$ acentuou os sintomas de deficiência de $\mathrm{Zn}$ e diminuiu os teores de Zn na parte aérea e nos bulbos. A deficiência de Mn normalmente é associada a valores elevados de $\mathrm{pH}$, decorrentes da calagem excessiva. Nylund (1952) aplicou vários micronutrientes (Mn, $\mathrm{Cu}, \mathrm{Fe}, \mathrm{Zn}$ e B) na cultura da cebola em um solo com pH 6,9 e verificou que somente o Mn aumentou a produtividade de bulbos: a máxima produtividade ocorreu com a aplicação de $35,5 \mathrm{~kg} \mathrm{ha}^{-1}$ de Mn, via solo, ou com $7,10 \mathrm{~kg}$ ha ${ }^{-1}$ de Mn em três pulverizações foliares. El-Tohamy et al. (2009) avaliaram o efeito de aplicações foliares com Mn, Zn e Fe na cultura da cebola, em solo arenoso, e obtiveram incrementos no diâmetro dos bulbos, no peso de bulbos frescos e na produtividade total para os três nutrientes, nas duas safras avaliadas.

A maioria dos cebolicultores de Santa Catarina, em especial da microrregião de Ituporanga, está adubando excessivamente a cultura, tanto no solo como com pulverizações foliares, pois existe grande pressão dos setores comerciais ligados à indústria de fertilizantes. Essa prática tem contribuído para elevar os custos de produção e os desequilíbrios nutricionais. Apesar disso, não existem trabalhos de pesquisa na região avaliando o efeito dessas técnicas na produtividade, na qualidade e na conservação dos bulbos de cebola. O presente trabalho objetivou, portanto, avaliar o efeito da adição de B, de Zn e de Mn ao solo, ou por meio de pulverizações foliares, na produtividade e na conservação de bulbos de cebola em áreas que vêm sendo cultivadas intensivamente com essa espécie.

\section{MATERIAL E MÉTODOS}

Este trabalho foi constituído por três experimentos, nos quais foi testada, respectivamente, a resposta da cultura da cebola (Allium cepa $\mathrm{L}$.) à adição de $\mathrm{Zn}, \mathrm{B}$ e Mn. Eles foram conduzidos no campo, nas safras 2006/ 2007, 2007/2008 e 2008/2009, na Estação Experimental da Empresa de Pesquisa Agropecuária e Extensão Rural de Santa Catarina (EPAGRI), situada a $475 \mathrm{~m}$ de altitude, $27^{\circ} 22^{\prime}$ ' S de latitude e $49^{\circ} 35^{\prime} \mathrm{W}$ de longitude, no município de Ituporanga, na região do Alto Vale do Itajaí, SC. Nas duas primeiras safras (2006/2007 e 2007/2008), os experimentos foram conduzidos na mesma área experimental, sem reaplicação dos fertilizantes no segundo ano. Na safra 2008/2009, os fertilizantes foram aplicados novamente, pois os experimentos foram realizados em outra área, próxima da primeira. Nas áreas experimentais, o solo é classificado como Cambissolo Háplico Tb distrófico (Embrapa, 1999). Em todas as áreas experimentais, o cultivo de cebola vem sendo realizado há vários anos, no sistema de sucessão de culturas. Por ocasião da implantação dos experimentos, o solo apresentou $\mathrm{pH}_{\mathrm{H} 2 \mathrm{O}}=5,9$, matéria orgânica $=38 \mathrm{~g} \mathrm{~kg}^{-1}$, P-Mehlich-1 = $12 \mathrm{mg} \mathrm{kg}^{-1}, \mathrm{~K}$ Mehlich-1 $=0,61 \mathrm{cmol}_{\mathrm{c}} \mathrm{kg}^{-1}$, Ca trocável = $6,7 \mathrm{cmol}_{\mathrm{c}} \mathrm{kg}^{-1}, \mathrm{Mg}$ trocável $=3,5 \mathrm{cmol}_{\mathrm{c}} \mathrm{kg}^{-1}, \mathrm{Zn}=$ $2,2 \mathrm{mg} \mathrm{kg}^{-1}, \mathrm{Mn}=48,5 \mathrm{mg} \mathrm{kg}^{-1}, \mathrm{~B}=0,8 \mathrm{mg} \mathrm{kg}^{-1}$, $\mathrm{CTC}_{\mathrm{pH} 7}=14 \mathrm{cmol}_{\mathrm{c}} \mathrm{kg}^{-1}$, além de 480, 360 e $160 \mathrm{~g} \mathrm{~kg}^{-1}$ de argila, silte e areia, respectivamente. Zinco e Mn foram extraídos com $\mathrm{HCl}$ 0,1 mol L-1 e determinados por espectrofotometria de absorção atômica; B foi extraído com água quente e determinado por colorimetria, usando curcumina. Todas as determinações no solo foram feitas de acordo com métodos descritos por Tedesco et al. (1995).

Em todos os experimentos foi usada a mesma sistemática de tratamentos. Em cada um deles foram utilizadas quatro doses do nutriente no solo, incluindo a testemunha e uma dose pulverizada na parte aérea das plantas, em seis ocasiões em cada ciclo vegetativo. No experimento de Zn, as doses aplicadas ao solo foram de $0,1,2$ e $4 \mathrm{~kg} \mathrm{ha}^{-1}$ de $\mathrm{Zn}$, e as pulverizações foliares foram realizadas na concentração de $0,5 \%$ do produto comercial, ambos na forma de sulfato de zinco. No experimento de $\mathrm{B}$, as doses aplicadas ao solo foram de 0; 1, 1; 2,2; e 4,4 kg ha-1 de B na forma de bórax, e as pulverizações foram feitas com ácido bórico na concentração de $0,25 \%$ do produto comercial. No experimento de $\mathrm{Mn}$, as doses aplicadas ao solo foram de $0 ; 3,9 ; 7,8$; e $15,6 \mathrm{~kg} \mathrm{ha}^{-1}$ de $\mathrm{Mn}$ e as pulverizações foram realizadas na concentração de $1,0 \%$ do sal, ambos na forma de sulfato de manganês.

As doses de B, Zn e Mn foram aplicadas ao solo na forma líquida, pela dissolução prévia dos respectivos fertilizantes sólidos em 6,0 L de água, com o objetivo de facilitar a uniformidade da aplicação em toda a área superficial de cada parcela. A seguir, eles foram incorporados até $10 \mathrm{~cm}$ de profundidade pela passagem de enxada rotativa e, no mesmo dia, efetuou-se o transplante das mudas. As pulverizações foliares iniciaram-se 15 dias após o transplante das mudas e estenderam-se até a fase de pleno enchimento dos bulbos, com intervalos de 14 dias. Elas foram realizadas com um volume de solução equivalente a $400 \mathrm{~L} \mathrm{ha}^{-1}$, por meio de um pulverizador manual.

Nitrogênio, P e K foram aplicados em todas as unidades experimentais, imediatamente após a 
aplicação dos tratamentos de solo, antes do transplante das mudas, sendo também incorporados na profundidade de $10 \mathrm{~cm}$. Foi adicionado o equivalente a 44, 160 e $58 \mathrm{~kg} \mathrm{ha}^{-1}$ de $\mathrm{N}, \mathrm{P}_{2} \mathrm{O}_{5}$ e $\mathrm{K}_{2} \mathrm{O}$, respectivamente, por meio da fórmula 09-33-12. Aos 45 dias após o transplante das mudas, foram adicionados mais $60 \mathrm{~kg} \mathrm{ha}^{-1}$ de $\mathrm{N}$ sobre a superfície do solo, na forma de sulfato de amônio.

O controle de plantas invasoras, de pragas e de doenças foi efetuado por meio de pulverizações com pesticidas químicos registrados e aprovados no Ministério da Agricultura, Pecuária e Abastecimento para uso na cultura da cebola.

A colheita dos bulbos foi sempre realizada entre os dias 15 e 20 de novembro, quando aproximadamente $70 \%$ das plantas apresentavam tombamento da parte aérea (estalamento), totalizando aproximadamente 110 dias de cultivo. Após serem arrancados, os bulbos foram dispostos sobre a superfície do solo, onde permaneceram por 15 dias até a conclusão da pré-cura. Após esse período, eles foram contados, pesados e acondicionados em sacos de ráfia telados, próprios para a comercialização de cebola. A seguir, os bulbos foram armazenados em galpão até meados de abril, totalizando aproximadamente 145 dias. Nessa ocasião, as ramas foram cortadas, e os bulbos, novamente contados, pesados e classificados de acordo com o estádio de conservação (deteriorados ou sadios).

Além dos atributos relacionados com a produtividade, foi também determinada a concentração de nutrientes nas folhas e no solo. As folhas (15 por parcela), sempre a mais alta da planta, foram coletadas por ocasião do início da bulbificação (CQFSRS/SC, 2004), que ocorreu próximo de 15 de outubro. Posteriormente, elas foram secas em estufa a $60{ }^{\circ} \mathrm{C}$ e moídas até passarem em peneiras com malhas de $1 \mathrm{~mm}$ de abertura. As folhas da safra 2006/ 2007 foram digeridas pelo método de combustão seca (Embrapa, 2002); as das demais safras, por digestão ácida (Tedesco et al., 1995). As amostras de solo foram coletadas após a colheita dos bulbos, num total de seis subamostras por parcela. Nelas, foram determinados os valores de $\mathrm{pH}$, matéria orgânica, $\mathrm{P}, \mathrm{K}, \mathrm{Ca}$ e $\mathrm{Mg}$ em todas as unidades experimentais de todos os experimentos, e o teor de $\mathrm{Zn}$, B ou Mn, somente nas parcelas de cada um dos respectivos experimentos. Todas as determinações analíticas foram realizadas de acordo com os métodos descritos por Tedesco et al. (1995).

Em todos os experimentos, utilizaram-se quatro repetições, distribuídas no delineamento experimental de blocos casualizados. As unidades experimentais tinham $12 \mathrm{~m}^{2}(3 \times 4 \mathrm{~m})$, e somente os $6,40 \mathrm{~m}^{2}$ centrais foram utilizados para as avaliações. Para avaliar o efeito das doses de nutrientes aplicadas ao solo, foi utilizada a análise de regressão; o efeito da pulverização foliar foi comparado com os demais tratamentos pelo uso da técnica de contrastes.

\section{RESULTADOS E DISCUSSÃO}

\section{Experimento de zinco}

A adição de $\mathrm{Zn}$ ao solo aumentou a produtividade de bulbos de cebola de forma quadrática (Figuras 1, 2 e 3). Nas três safras (2006/2007, 2007/2008 e 2008/ 2009), o rendimento aumentou, respectivamente, de 19,4 para $22,4 \mathrm{t} \mathrm{ha}^{-1}$, de 14,0 para $16,8 \mathrm{t} \mathrm{ha}^{-1}$ e de 31,9 para $35,1 \mathrm{t} \mathrm{ha}^{-1}$, correspondendo a um incremento médio de 13,5\% (com valores extremos entre 11 e $15 \%$ ). Para obtenção da máxima eficiência técnica estimada, foi necessário adicionar em média $3,5 \mathrm{~kg} \mathrm{ha}^{-1}$ de $\mathrm{Zn}$, cujos valores variaram de $2,7 \mathrm{~kg} \mathrm{ha}^{-1}$ na safra $2006 / 2007$ a $4,3 \mathrm{~kg} \mathrm{ha}^{-1}$ na safra $2008 / 2009$. Na safra 2007/2008, foi avaliado o efeito residual das doses aplicadas na safra anterior, e a produtividade máxima foi obtida pela adição de $3,5 \mathrm{~kg} \mathrm{ha}^{-1}$.

A aplicação de $\mathrm{Zn}$ nas folhas não alterou a produtividade de cebola em nenhuma safra. A análise de contrastes mostrou que utilização de seis
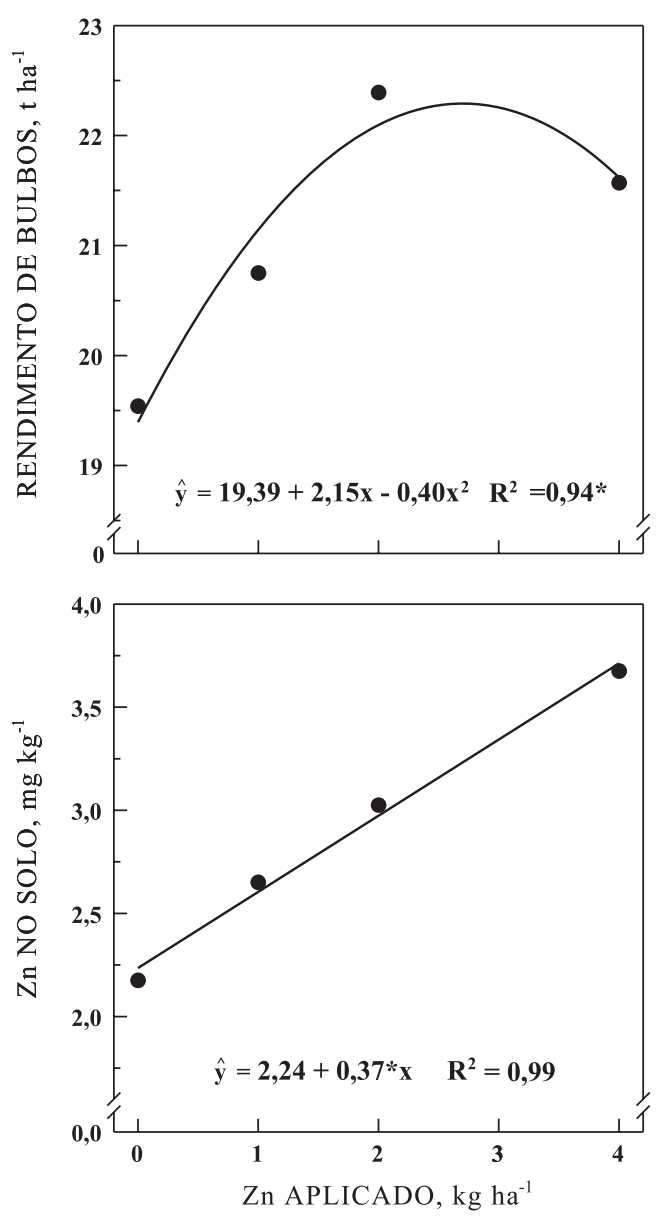

Figura 1. Produtividade de bulbos de cebola e teor de Zn no solo na safra 2006/2007, em função da adição de doses crescentes de $\mathrm{Zn}$ ao solo antes do plantio. Média de quatro repetições. * Significativo $(p<5 \%)$. 

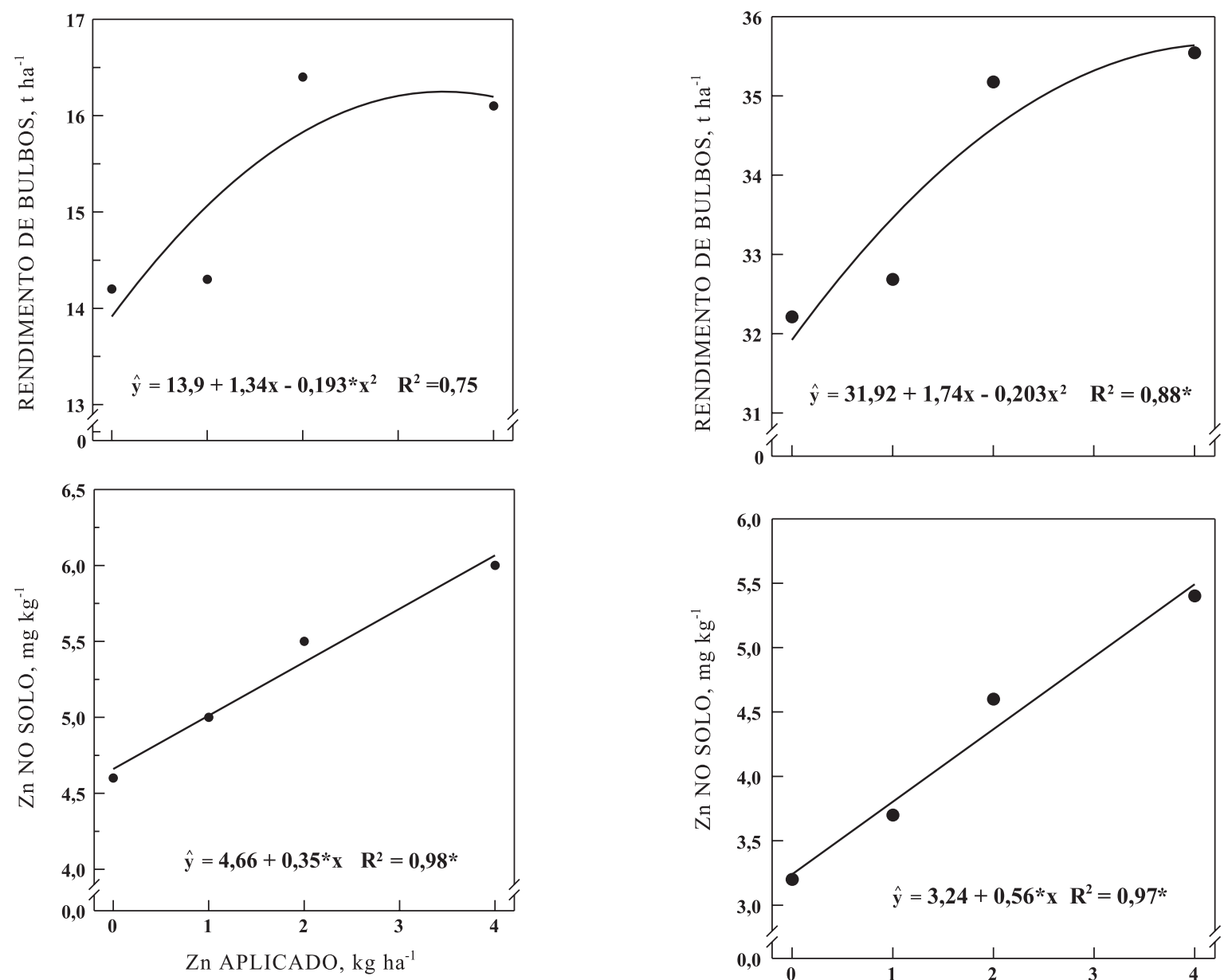

Figura 2. Produtividade de bulbos de cebola e teor de Zn no solo na safra 2007/2008, em função da adição de doses crescentes de $\mathrm{Zn}$ ao solo antes do plantio da safra 2006/2007. Média de quatro repetições. * Significativo $(\mathrm{p}<5 \%)$.

pulverizações foliares com sulfato de zinco, na concentração de $0,5 \%$, proporcionou produtividade de bulbos semelhante à da testemunha, onde não foi aplicado Zn (Quadro 1). Quando o tratamento com $\mathrm{Zn}$ foliar foi comparado com todos os demais tratamentos aplicados via solo, ele mostrou-se inferior.

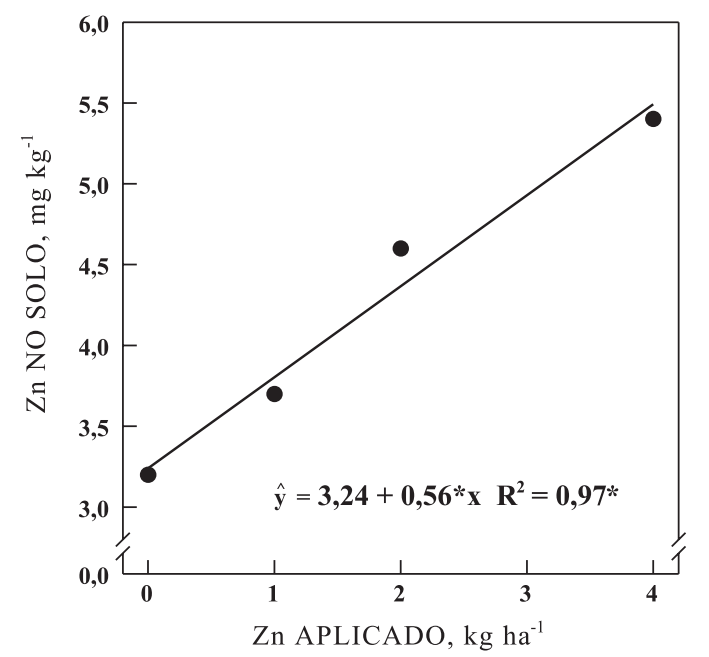

Figura 3. Produtividade de bulbos de cebola e teor de Zn no solo na safra 2008/2009, em função da adição de doses crescentes de $\mathrm{Zn}$ ao solo antes do plantio. Média de quatro repetições. * Significativo $(p<5 \%)$.

Vários autores observaram que a adição de Zn tem aumentado a produtividade de cebola em diversas situações. Foi o que aconteceu com Peña et al. (1999) na Venezuela, que obtiveram incremento de $28 \%$ pela aplicação de 2,52 $\mathrm{kg} \mathrm{ha}^{-1}$ de Zn; com Gupta et al. (1985) na Índia, onde o incremento foi de 30 \% pela

Quadro 1. Contrastes ortogonais para a comparação do efeito do $\mathrm{Zn}$ aplicado via foliar (seis pulverizações) com a testemunha (sem $\mathrm{Zn}$ ) ou com a média das doses de $\mathrm{Zn}$ aplicadas ao solo $\left(1,2\right.$ e $\left.4 \mathrm{~kg} \mathrm{ha}^{-1}\right)$ no rendimento de bulbos de cebola em três safras agrícolas

\begin{tabular}{ccccccc}
\hline \multirow{2}{*}{ Safra } & \multicolumn{5}{c}{ Rendimento } \\
\cline { 2 - 7 } & Testemunha & Aplicação foliar & Significância & Aplicação foliar & No solo & Significância \\
\hline & & $\mathrm{t} \mathrm{ha}^{-1}$ & & $\mathrm{t} \mathrm{ha}^{-1}$ & & \\
$2006-2007$ & 19,5 & 20,0 & $\mathrm{p}=0,36^{\mathrm{ns}}$ & 20,0 & 21,6 & $\mathrm{p}=0,004^{* *}$ \\
$2007-2008$ & 14,2 & 14,2 & $\mathrm{p}=0,51^{\mathrm{ns}}$ & 14,2 & 15,6 & $\mathrm{p}=0,049^{*}$ \\
$2008-2009$ & 32,2 & 31,9 & $\mathrm{p}=0,82^{\mathrm{ns}}$ & 31,9 & 34,5 & $\mathrm{p}=0,019^{*}$ \\
\hline
\end{tabular}

ns: não significativo $(\mathrm{p}=0,05)$. 
adição de $5 \mathrm{~kg}$ ha-1 de Zn; e com Asif et al. (1975) em solo arenoso da Nigéria. El-Tohamy et al. (2009) avaliaram o efeito da aplicação de micronutrientes na produtividade de cebola em um solo arenoso do Egito. Eles pulverizaram as folhas de cebola com $\mathrm{Zn}$, na concentração de $0,3 \mathrm{~g} \mathrm{~L}^{-1}$, e verificaram incrementos no rendimento de 60 e de $43 \%$ nas safras 2006 e 2007 , respectivamente. Em algumas circunstâncias, entretanto, não tem havido resposta da cultura da cebola à adição de Zn ao solo (Nylund, 1952; Campbell \& Gusta, 1965).

A adição de $\mathrm{Zn}$ ao solo aumentou linearmente o teor do nutriente no solo extraído com $\mathrm{HCl} \mathrm{0,1} \mathrm{mol} \mathrm{\textrm {L } ^ { - 1 }}$ (Figuras 1, 2 e 3). Para cada $\mathrm{kg} \mathrm{ha}^{-1}$ de $\mathrm{Zn}$ adicionado, houve incremento no $\mathrm{Zn}$ do solo de 0,37 e 0,56 $\mathrm{mg} \mathrm{kg}^{-1}$, respectivamente nas safras 2006/2007 e 2008/2009. $\mathrm{Na}$ safra 2007/2008, em que foi avaliado o efeito residual do $\mathrm{Zn}$ aplicado ao solo na safra anterior, a recuperação foi de $70 \%$ do aplicado. Valores de Zn recuperados acima de $80 \%$ da quantidade aplicada já haviam sido obtidos em experimento com vasos em um Latossolo catarinense (Ernani et al., 2001). As tabelas oficiais de recomendação de adubação utilizadas nos Estados do RS e de SC mencionam que, a partir de $0,5 \mathrm{mg} \mathrm{kg}^{-1}$ de $\mathrm{Zn}$ no solo, é baixa ou nula a possibilidade de a aplicação desse nutriente aumentar a produtividade das culturas (CQFSRS/SC, 2004). No presente trabalho, entretanto, o solo apresentava entre 2,2 e 3,2 mg kg-1 de Zn e mesmo assim a aplicação desse nutriente incrementou o rendimento de bulbos de cebola. Isso pode ser explicado pela alta exigência da cebola por $\mathrm{Zn}$ e, também, pelo seu pequeno sistema radicular, o que resulta na exploração de um menor volume de solo em relação a outras culturas, requerendo, portanto, maior concentração de Zn no solo.

A adição de Zn ao solo não alterou o peso médio de bulbos, independentemente da safra (Quadro 2). A adição de $\mathrm{Zn}$ às folhas, num total de seis pulverizações durante o ciclo vegetativo, proporcionou menor peso do bulbo do que a aplicação de Zn ao solo, porém semelhante ao do tratamento em que não foi aplicado Zn (testemunha), nas três safras, na avaliação feita por meio de contrastes. Resultados semelhantes aos deste experimento foram obtidos por Peña et al. (1999), que constataram aumento na produtividade de bulbos pela adição de $\mathrm{Zn}$, mas também não tiveram aumento no peso médio deles. Contudo, Lal \& Maurya (1983) observaram que o maior peso dos bulbos secos e frescos foi obtido com a aplicação de $6 \mathrm{~kg} \mathrm{ha}^{-1}$ de $\mathrm{Zn}$ em um experimento conduzido por dois anos. Asif et al. (1975) também verificaram resposta positiva da aplicação de Zn no peso tanto da parte aérea quanto dos bulbos secos.

A aplicação de $\mathrm{Zn}$ ao solo ou por meio de pulverizações foliares não alterou o nível de perda de cebola no armazenamento (Quadro 3). A perda média encontrada variou entre 26 e 35 \%. Nas avaliações feitas nos bulbos armazenados, verificou-se alta variabilidade em todos os tratamentos e repetições,
Quadro 2. Peso médio de bulbos, perda de peso no armazenamento e concentração de $\mathrm{Zn}$ na folha de cebola, em função da adição de doses crescentes de $\mathrm{Zn}$ ao solo ou de seis pulverizações foliares com sulfato de zinco $0,5 \%$ nas safras 2006/2007, 2007/2008 e 2008/2009

\begin{tabular}{|c|c|c|c|}
\hline Tratamento & $\begin{array}{l}\text { Peso de } \\
\text { bulbo }\end{array}$ & $\begin{array}{c}\text { Perda no } \\
\text { armazenamento }\end{array}$ & Zn na folha \\
\hline \multirow[t]{2}{*}{$\mathrm{kg} \mathrm{ha}^{-1}$} & $\mathrm{~g}$ & $\%$ & $\mathrm{mg} \mathrm{kg}^{-1}$ \\
\hline & & Safra 2006/07 & \\
\hline 0 & $84^{*}$ & $22,3 \mathrm{~ns}$ & $14,1^{\mathrm{ns}}$ \\
\hline $1,0^{(1)}$ & 85 & 27,2 & 14,1 \\
\hline 2,0 & 92 & 28,7 & 13,6 \\
\hline 4,0 & 88 & 28,1 & 15,1 \\
\hline Foliar & 78 & 26,0 & 14,4 \\
\hline \multirow[t]{2}{*}{ Média } & 85 & 26,5 & 14,3 \\
\hline & & Safra 2007/08 & \\
\hline 0 & $65^{*}$ & $42,2^{\mathrm{ns}}$ & $17,8^{*}$ \\
\hline $1,0^{(1)}$ & 60 & 23,1 & 17,5 \\
\hline 2,0 & 67 & 31,3 & 19,3 \\
\hline 4,0 & 70 & 38,1 & 18,8 \\
\hline Foliar & 60 & 38,6 & 25,3 \\
\hline \multirow[t]{2}{*}{ Média } & 64 & 34,7 & 19,7 \\
\hline & & Safra 2008/09 & \\
\hline 0 & $144^{*}$ & $28,7 \mathrm{~ns}$ & $18,8^{\mathrm{ns}}$ \\
\hline $1,0^{(1)}$ & 141 & 30,5 & 20,5 \\
\hline 2,0 & 152 & 27,4 & 19,3 \\
\hline 4,0 & 150 & 20,8 & 21,5 \\
\hline Foliar & 135 & 25,6 & 19,3 \\
\hline Média & 144 & 26,6 & 19,9 \\
\hline
\end{tabular}

(1) Aplicado na forma de sulfato de zinco e incorporado na camada de 0-10 cm de profundidade. ${ }^{\mathrm{ns}}$ Não significativo ( $\geq 5 \%$ ). * Estatisticamente significativo $(\mathrm{p}<5 \%){ }^{(2)}$ Para as doses aplicadas ao solo, usou-se análise de regressão; a comparação do tratamento foliar em relação aos demais foi feita por análise de contrastes.

que contribuíram para o alto coeficiente de variação. Essas perdas no armazenamento são comuns e foram ocasionadas principalmente pela deterioração dos bulbos devido à ocorrência de bacterioses e por desidratação. Vários estudos têm demonstrado que a nutrição da cultura da cebola pode alterar as perdas no armazenamento, mas elas são mais evidentes para $\mathrm{N}$ e B.

A aplicação de Zn nas safras 2006/2007 e 2008/ 2009 não alterou o teor deste nutriente nas folhas de cebola, independentemente da dose e do modo de aplicação do nutriente; na safra 2007/2008, entretanto, o tratamento em que foram feitas seis pulverizações foliares com $\mathrm{Zn}$ apresentou teor desse nutriente nas folhas maior do que os demais (Quadro 2), porém isso não refletiu em incremento na produtividade de bulbos (Figura 3). O teor médio de $\mathrm{Zn}$ nas folhas variou de 14,3, na safra 2006/2007, a aproximadamente $20 \mathrm{mg} \mathrm{kg}{ }^{-1}$, nas demais safras. A Comissão de Química e Fertilidade do Solo dos Estados do Rio Grande do Sul e de Santa Catarina considera que a faixa adequada de $\mathrm{Zn}$ nas folhas de cebola varia de 30 a $100 \mathrm{mg} \mathrm{kg}^{-1}$ (CQFSRS/SC, 2004). 


\section{Experimento de boro}

A aplicação de B, independentemente da dose e da forma aplicada (ao solo ou por meio de pulverizações foliares), não alterou a produtividade de bulbos de cebola (Quadro 3). O rendimento médio de cebola foi de $22,6,18,5$ e $38,3 \mathrm{t} \mathrm{ha}^{-1}$ nas três safras, respectivamente. Vários autores também não têm encontrado aumento de produtividade de cebola pela aplicação de B (Nylund, 1952; Rao \& Deshpande, 1971; Peña et al., 1999). Jayamohanrao (1974), entretanto, verificou que a aplicação de $1,8 \mathrm{~kg} \mathrm{ha}^{-1} \mathrm{de}$ B combinado com 13,4 $\mathrm{kg} \mathrm{ha}^{-1}$ de $\mathrm{Cu}$ aumentou em $43 \%$ o rendimento dos bulbos, na Índia. A ausência de resposta da cultura da cebola à aplicação de $\mathrm{B}$ no presente estudo pode ser explicada, em parte, pelos valores relativamente altos de matéria orgânica no solo $\left(38 \mathrm{~g} \mathrm{~kg}^{-1}\right)$. Outro fator que também pode ter contribuído para isso são os valores moderados de $\mathrm{pH}$ do solo $(5,6$ a 5,9), que favorecem a permanência de B na sua solução. Soprano \& Silva (1996) avaliaram o efeito do $\mathrm{pH}$ de um solo catarinense na produtividade de cebola, em casa de vegetação, e verificaram que as melhores produções foram obtidas entre $\mathrm{pH}$ 5,0 e 6,5; acima de $\mathrm{pH} 7,0$, a produção de matéria seca teve redução drástica e as plantas apresentaram sintomas de deficiência de $\mathrm{B}$, provavelmente devido à formação de boratos de cálcio de baixa solubilidade.
$\mathrm{O}$ peso de bulbos e a perda no armazenamento não foram alterados pela aplicação de B (Quadro 3). A perda média de bulbos armazenados por 145 dias variou de 19 a $29 \%$, situando-se dentro das médias ocorridas na região para as safras estudadas. No presente estudo não foi encontrada nenhuma evidência de aumento na qualidade dos bulbos de cebola pela adição de $\mathrm{B}$, contrariando resultados obtidos por diversos autores (Jayamohanrao, 1974; Calbo et al., 1986; Ferreira \& Minami, 2000).

A aplicação de B também não alterou os teores de B no solo na única safra em que essa determinação foi realizada (2006/2007), independentemente se aplicado ao solo ou pulverizado às folhas (Quadro 3). $\mathrm{O}$ teor médio de $\mathrm{B}$ encontrado no solo foi de $0,7 \mathrm{mg} \mathrm{kg}^{-1}$, considerado alto pelos padrões das instituições de pesquisa dos Estados do RS e de SC (CQFSRS/SC, 2004). O teor de B nas folhas de cebola, no entanto, aumentou com a adição do nutriente em duas das três safras (2007/2008 e 2008/2009) (Quadro 2). Na safra 2007/2008, o aumento aconteceu de forma quadrática com o incremento nas doses aplicadas no solo. Nas duas últimas safras (2007/2008 e 2008/2009), as pulverizações foliares com $\mathrm{B}$ proporcionaram maior teor de $\mathrm{B}$ nas folhas do que as doses desse nutriente aplicadas ao solo. O teor médio de $\mathrm{B}$ encontrado nas folhas das três safras variou de 13,4 a $26,3 \mathrm{mg} \mathrm{kg}^{-1}$

Quadro 3. Produtividade, peso médio de bulbos, perda no armazenamento, teor de B no solo e nas folhas de cebola, em função da adição de doses crescentes de $\mathrm{B}$ ao solo ou de seis pulverizações foliares com ácido bórico 0,25 \% nas safras 2006/2007, 2007/2008 e 2008/2009

\begin{tabular}{|c|c|c|c|c|c|}
\hline Tratamento & $\begin{array}{l}\text { Produtividade } \\
\text { de bulbos }\end{array}$ & Peso de bulbo & $\begin{array}{c}\text { Perda no } \\
\text { armazenamento }\end{array}$ & B no solo & B na folha \\
\hline $\mathrm{kg} \mathrm{ha}^{-1}$ & $\mathrm{t} \mathrm{ha}^{-1}$ & $\mathrm{~g}$ & $\%$ & $\mathrm{mg} \mathrm{kg}^{-1}$ & $\mathrm{mg} \mathrm{kg}^{-1}$ \\
\hline $\begin{array}{l}0 \\
1,1^{(1)} \\
2,2 \\
4,4 \\
\text { Foliar } \\
\text { Média }\end{array}$ & $\begin{array}{l}22,16^{\mathrm{ns}} \\
22,78 \\
22,70 \\
22,43 \\
23,13 \\
22,64\end{array}$ & $\begin{array}{l}90^{\mathrm{ns}} \\
93 \\
89 \\
92 \\
92 \\
91\end{array}$ & $\begin{array}{c}\text { Safra } 2006 / 07 \\
18,6 \mathrm{~ns} \\
18,3 \\
16,5 \\
19,0 \\
20,6 \\
18,6\end{array}$ & $\begin{array}{l}0,8 \text { ns } \\
0,7 \\
0,7 \\
0,6 \\
0,7 \\
0,7\end{array}$ & $\begin{array}{l}23,3 \mathrm{~ns} \\
29,0 \\
24,3 \\
28,8 \\
26,0 \\
26,3\end{array}$ \\
\hline $\begin{array}{l}0 \\
1,1^{(1)} \\
2,2 \\
4,4 \\
\text { Foliar } \\
\text { Média }\end{array}$ & $\begin{array}{l}19,32^{\mathrm{ns}} \\
17,44 \\
18,57 \\
19,64 \\
17,74 \\
18,54\end{array}$ & $\begin{array}{l}82^{\mathrm{ns}} \\
74 \\
75 \\
83 \\
76 \\
80\end{array}$ & $\begin{array}{c}\text { Safra } 2007 / 08 \\
34,3 \mathrm{~ns} \\
28,1 \\
27,8 \\
31,4 \\
23,1 \\
28,9\end{array}$ & & $\begin{array}{c}9,3^{*} \\
11,3 \\
15,3 \\
14,8 \\
16,3 \\
13,4\end{array}$ \\
\hline $\begin{array}{l}0 \\
1,1^{(1)} \\
2,2 \\
4,4 \\
\text { Foliar } \\
\text { Média }\end{array}$ & $\begin{array}{l}39,31^{\mathrm{ns}} \\
38,56 \\
38,35 \\
37,42 \\
37,68 \\
38,26\end{array}$ & $\begin{array}{l}174^{\mathrm{ns}} \\
172 \\
168 \\
165 \\
163 \\
168\end{array}$ & $\begin{array}{c}\text { Safra } 2008 / 09 \\
20,7 \mathrm{~ns} \\
23,4 \\
18,6 \\
24,9 \\
19,4 \\
21,4\end{array}$ & & $\begin{array}{l}24,5^{*} \\
23,8 \\
23,5 \\
22,0 \\
29,5 \\
24,7\end{array}$ \\
\hline
\end{tabular}

(1) Aplicado na forma de bórax e incorporado na camada de 0-10 cm de profundidade. ${ }^{\text {ns }}$ Não significativo (p $\geq 5$ \%). * Estatisticamente significativo $(\mathrm{p}<5 \%) .{ }^{(2)}$ Para as doses aplicadas ao solo, usou-se análise de regressão; a comparação do tratamento foliar em relação aos demais foi feita por análise de contrastes. 
(Quadro 3). Em duas safras, os valores médios são considerados abaixo da faixa adequada, que varia de 25 a $75 \mathrm{mg} \mathrm{kg}^{-1}$ (Mesquita Filho et al., 2001) e de 30 a $50 \mathrm{mg} \mathrm{kg}^{-1}$ (CQFSRS/SC, 2004).

\section{Experimento de manganês}

A aplicação de Mn não alterou a produtividade, o peso médio de bulbos e a perda no armazenamento em nenhuma das três safras avaliadas (Quadro 4), independentemente do método de aplicação (ao solo ou via foliar). A produtividade de bulbos foi de 22,3, 18,5 e 37,4 t ha $^{-1}$ nas safras 2006/2007, 2007/2008 e 2008/ 2009, respectivamente. As perdas de bulbos após 145 dias de armazenamento variaram de 19,7 a $33 \%$, situando-se dentro das médias obtidas pelos produtores em cada uma das safras.

O efeito da aplicação de Mn na produtividade de bulbos de cebola tem sido muito variável. El-Tohamy et al. (2009) pulverizaram Mn em folhas de cebola cultivada em solo arenoso do Egito, na concentração de $0,1 \%$, e obtiveram incremento na produtividade de 53 e de $41 \%$ nas safras 2006 e 2007, respectivamente. Werner (1996) aplicou Mn ao solo (entre 1 e $4 \mathrm{~kg}$ ha 1) e em pulverizações foliares (em concentrações de até $2,5 \%$ de sulfato de manganês) em áreas catarinenses onde as plantas apresentavam sintomas de deficiência de Mn e, mesmo assim, não verificou nenhum aumento no rendimento ou no peso médio dos bulbos. Campbell \& Gusta (1966) aplicaram Mn, Zn e Cu em solo orgânico, no Canadá, e constataram que somente o $\mathrm{Cu}$ aumentou a produtividade de cebola. No entanto, Nylund (1952) avaliou o efeito da adição de B, Cu, Fe e Zn ao solo, e de Mn via solo e foliar, num solo com pH 6,9, nos EUA, e verificou que somente o Mn aumentou a produtividade de cebola. A fonte utilizada foi o $\mathrm{MnSO}_{4}$, e a dose que proporcionou a maior produtividade foi de $37,5 \mathrm{~kg} \mathrm{ha}^{-1}$ de $\mathrm{Mn}$, adicionada ao solo, ou 7,5 $\mathrm{kg} \mathrm{ha}^{-1}$ de $\mathrm{Mn}$, divididos em três pulverizações foliares. Bührer et al. (1996) obtiveram aumentos na produtividade de cebola pela aplicação de sulfato de manganês tanto ao solo quanto por meio de pulverizações foliares, em Ituporanga, SC. Os melhores resultados ocorreram com 12 pulverizações foliares, nas concentrações de 1 ou $0,5 \%$, ou com $8 \mathrm{~kg} \mathrm{ha}^{-1}$ de sulfato de Mn adicionado ao solo. Resultados similares foram obtidos em outras áreas da região que apresentavam sintomas de deficiência de $\mathrm{Mn}$ (Boing et al., 1996). Em Santa Catarina, nas áreas onde as plantas têm apresentado sintomas de deficiência de $\mathrm{Mn}$, o pH do solo geralmente é maior do que 6,0, há predomínio de monocultivo e, em geral, o teor de matéria orgânica é baixo e os solos são intensivamente cultivados e degradados (Werner et al., 1996). No presente estudo, a ausência de incremento na produtividade de cebola pela aplicação de Mn provavel-

Quadro 4. Produtividade, peso médio de bulbos, perda no armazenamento, teor de Mn no solo e nas folhas de cebola, em função da adição de doses crescentes de Mn ao solo ou de seis pulverizações foliares com sulfato de manganês 1,0 \% nas safras 2006/2007, 2007/2008 e 2008/2009

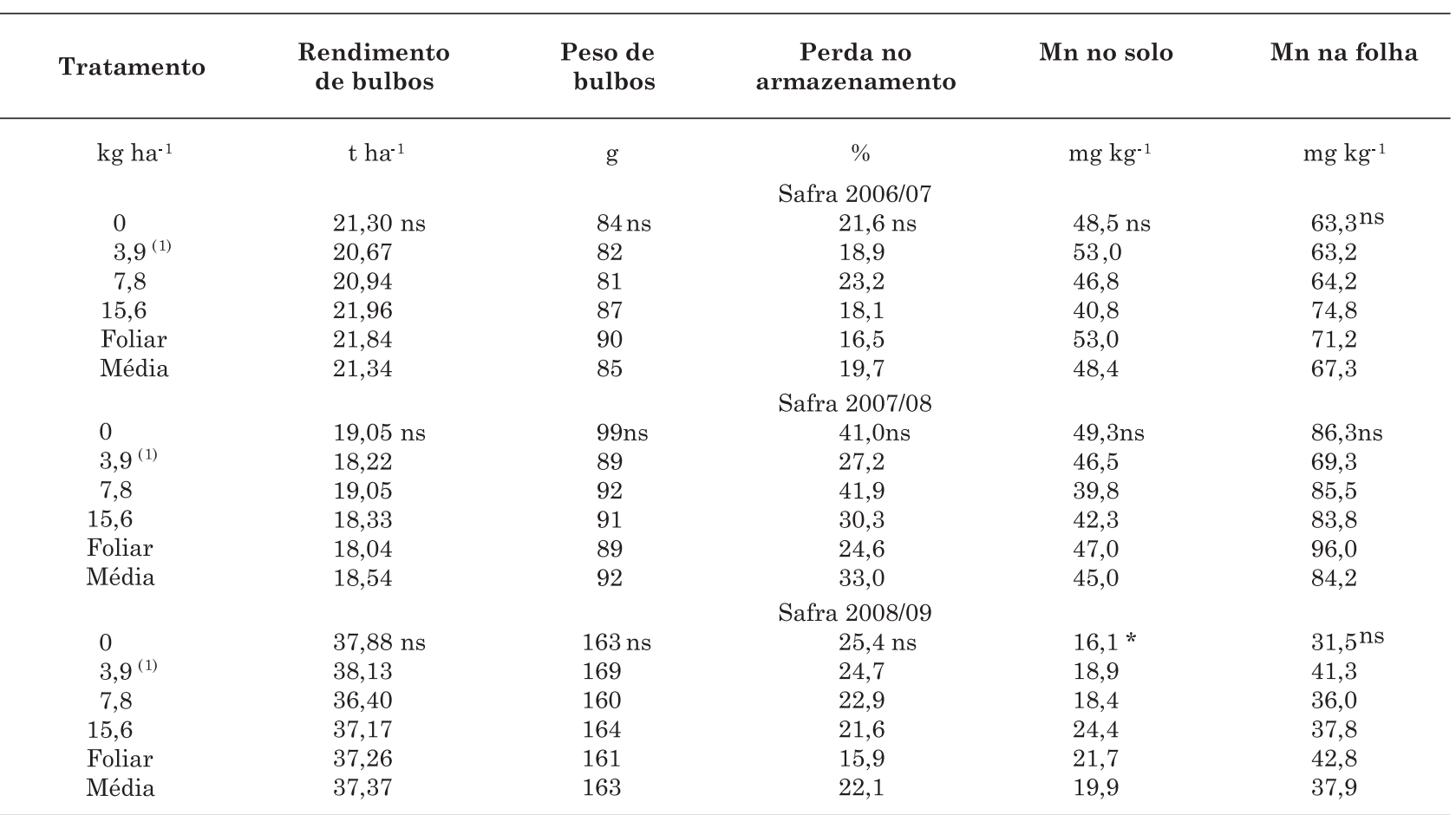

${ }^{(1)}$ Aplicado na forma de bórax e incorporado na camada de 0-10 cm de profundidade. ${ }^{\text {ns }}$ Não significativo ( $\mathrm{p} \geq 5$ \%). * Estatisticamente significativo $(\mathrm{p}<5 \%){ }^{(2)}$ Para as doses aplicadas ao solo, usou-se análise de regressão; a comparação do tratamento foliar em relação aos demais foi feita por análise de contrastes. 
mente se deve ao valor de $\mathrm{pH}$ relativamente baixo das áreas experimentais $(5,6$ a 5,9).

A aplicação de $\mathrm{Mn}$, independentemente do método de aplicação (ao solo ou nas folhas), também não influenciou o teor de Mn no solo e nas folhas de cebola, à exceção do teor de Mn no solo na safra 2008/2009 (Quadro 3). Nesta última safra, os teores de Mn no solo aumentaram linearmente com o aumento das doses de Mn aplicadas ao solo. O teor na testemunha, que não recebeu $\mathrm{Mn}$, extraído do solo com $\mathrm{KCl}$ 1,0 $\mathrm{mol} \mathrm{L}^{-1}$, variou com a safra, de 16,1 a $49 \mathrm{mg} \mathrm{kg}^{-1}$. Esses valores são elevados quando comparados com o teor considerado alto para os solos da região Sul, que é de $5 \mathrm{mg} \mathrm{kg}^{-1}$ (CQFSRS/SC, 2004), e podem justificar a ausência de resposta a esse nutriente pela cebola. Os teores foliares médios encontrados variaram de 37,9 a $84,2 \mathrm{mg} \mathrm{kg}^{-1}$ e são considerados normais nas duas primeiras safras e um pouco abaixo na última safra, segundo Mesquita Filho (2001) e Vidigal et al. (2002), que mencionam a faixa adequada de Mn nas folhas de cebola como de 50 a 250 e de 50 a $300 \mathrm{mg} \mathrm{kg}^{-1}$, respectivamente.

\section{CONCLUSÕES}

1. Em Cambissolos catarinenses com $\mathrm{pH}$ próximo de 6,0 não há necessidade de aplicar $\mathrm{B}$ ou Mn à cultura da cebola, tanto no solo como por meio de pulverizações foliares.

2. É recomendável a aplicação de Zn ao solo ainda que o nível crítico esteja acima do indicado pelos órgãos regionais de pesquisa.

3. Nenhum dos três micronutrientes aplicados (B, Mn e Zn) alterou a conservação dos bulbos durante o armazenamento.

\section{LITERATURA CITADA}

ALLOWAY, B.J. Zinc in soils and crop nutrition. Belgium, 2004. Disponível em: < http://www.zincworld.org> Acesso em 15 set. 2007.

ASIF, M.I.; KHAN, A.A. \& AJAKAIYE, M.N. Zinc nutrition of onions as influenced by phosphorus. J. Agric. Sci., 87:277. 279, 1976

BATAGLIA, O.C. Micronutrientes: Disponibilidade e interações. In: BORKERT, C.M. \& LANTMANN, A.F., eds. Enxofre e micronutrientes na agricultura brasileira. Londrina, 1988. p.121-130.

BÜHRER, R.R.; WERNER, H. \& DEBARBA, J.F. Unidade de observação de adubação de manganês na cultura da cebola. In: REUNIÃO DE PESQUISA DA CEBOLA NO MERCOSUL, Ituporanga, 1996. Anais. Ituporanga, Epagri, 1996. p.55.
BOING, J.; WERNER, H. \& DEBARBA, J.F. Unidade de observação de adubação de manganês na cultura da cebola no município de Imbuia (SC). In: REUNIÃO DE PESQUISA DA CEBOLA NO MERCOSUL, Ituporanga, 1996. Anais. Ituporanga, Epagri, 1996. p.56.

BOEING, G. Cebola - Preços recebidos não remuneram a atividade. Inf. Conjuntural. Florianópolis. Mar. 2007. Disponível em: <http://www.cepa.epagri.sc.gov.br >. Acesso em 5 mar. 2007.

CAMARGO, O.A.; VALADARES, J.M.A.S. \& DECHEN, A.R. Efeitos do $\mathrm{pH}$ e da incubação na extração de manganês, zinco, cobre e ferro do solo. R. Bras. Ci. Solo, 6:83-88, 1982.

CALBO, M.E.R.; MONNERAT, P.H. \& CHIMOYA, C. Caracterização de sintomas de deficiência de boro em cebola (Allium cepa L.) em estádio de produção. R. Ceres, 33:274-280, 1986.

CAMPBELL, I.D. \& GUSTA, L.V. The response of carrots and onion to micronutrients on organic soil in Manitoba. Canadian J. Plant Sci., 47:419-423, 1965.

COMISÃO DE QUÍMICA E FERTILIDADE DO SOLO CQFSRS/SC. Manual de adubação e calagem para os Estados do Rio Grande do Sul e de Santa Catarina. 10.ed. Porto Alegre, Sociedade Brasileira de Ciência do Solo/ Núcleo Regional Sul/ Universidade Federal do Rio Grande do Sul, 2004. 394p.

EL-TOHAMY, W.A.; KHALID, A.K.; EL-ABAGY, H.M. \& ABOU-HUSSEIN, S.D. Essential oil, growth and yield of onion (Allium Cepa L.) in response to foliar application of some micronutrients. Aust. J. Basic Appl. Sci., 3:201-2005, 2009 .

EMPRESA BRASILEIRA DE PESQUISA AGROPECUÁRIA EMBRAPA. Sistema brasileiro de classificação de solos. Brasília, 1999. 412p.

EMPRESA BRASILEIRA DE PESQUISA AGROPECUÁRIA EMBRAPA. Manual de métodos de análises de solos. 2.ed. Rio de Janeiro, 2002. 212p.

EMPRESA DE PESQUISA AGROPECUÁRIA E EXTENSÃO RURAL DE SANTA CATARINA - EPAGRI. Sistemas de produção para cebola: Santa Catarina ( $3^{\text {a }}$ revisão). Florianópolis, Epagri, 2000. 91p. (Sistemas de Produção, 16)

ERNANI, P.R. Química do solo e disponibilidade de nutrientes às plantas. Lages, 2008. 229p.

ERNANI, P.R.; BITTENCOURT, F.; VALMORBIDA, J. \& CRESTANI, J. Influência de adições sucessivas de zinco, na forma de esterco suíno ou de óxido, no rendimento de matéria seca de milho. R. Bras. Ci. Solo, 25:905-911, 2001.

FERREIRA, M.D. \& MINAMI, K. Qualidade de bulbos de cebola em conseqüência de tratamentos em pré-colheita. Sci. Agríc., 57:693-701, 2000.

GUPTA, V.K.; RAJ, H. \& GUPTA, S.P. A note on effect of zinc application on the yield and zinc concentration of onion (Allium cepa L.). Haryana J. Hortic. Sci., 12:141-142, 1985. 
JAYMOHANRAO, V. Effect of copper and boron on the mineral composition of onion (Allium cepa L). Andhra Agric. J., 17:170-172, 1974.

KREBS, R.; GUPTA, S.K.; FURRER, G. \& SCHULIN, R. Solubility and plant uptake of metals with liming of sludgeamended soils. J. Environ. Qual., 27:18-23, 1988.

LAL, S. \& MAURYA, A.N. Effects of zinc on onion. Haryana J. Hortic. Sci., 10:231-235, 1983.

MESQUITA FILHO, M.V.; SOUZA, A.F. \& FURLANI, P.R. Hortaliças de bulbo, tubérculo, raiz e fruto. In: FERREIRA, M.E.; CRUZ, M.C.P.; RAIJ, B.van \& ABREU, C.A., eds. Micronutrientes e elementos tóxicos na agricultura. Jaboticabal, CNPq/FAPESP/POTAFOS, 2001. p.511-525.

MORTVEDT, J.J. Micronutrient fertilizer technology. In: MORTVEDT, J.J.; COX, F.R.; SHUMAN, L.M. \& WELCH., R.M., eds. Micronutrients in agriculture. 2.ed. Madison, Soil Science Society of America, 1991. 760p.

NYLUND, R.E. The response of onions to soil and foliar applications of manganese and to soil applications of other trace elements. Proc. Am. Soc. Hortic. Sci., 60:283-285, 1952 .

PEÑA, C.; AÑES, B. \& DÁVILA, M. Respuesta de la cebolla (Allium cepa L.) a la aplicación de azufre, magnesio, cinc, y boro en un suelo alcalino. Rev. For., 43:173-182, 1999.

RAFIQUE, E.; MAHMOOD-UL-HASSAN, M.; KHOKHAR, K.M.; NABI, G. \& TABASSAM, T. Zinc nutrition of onion: Proposed diagnostic criteria. J. Plant Nutr., 31:307-316, 2008.
RAO, V.J.M. \& DESHPANDE, R. Effect of micronutrients (copper and boron) on the growth and yield of onion (Allium cepa 1.). Indian J. Agric. Res., 5:257-260, 1971.

RIBEIRO, M.E.M. Caracterização de sintomas de deficiências de boro em pepino, alface, alho, beterraba, cebola e rabanete. Viçosa, MG, Universidade Federal de Viçosa, 1978. 48p. (Tese de Mestrado)

SOPRANO, E. \& SILVA JUNIOR, A.A. Efeito de níveis de pH do solo sobre o crescimento da cebola em casa de vegetação. In: REUNIÃO DE PESQUISA DA CEBOLA NO MERCOSUL, Ituporanga, Epagri, 1996. p.59.

TANAKA, T.; NISHIRAWA, T. \& KAWASAKI, S. Experimentos de adubação e calagem em cultura de cebola por meio de bulbinho. Pesq. Agropec. Bras., 5:61-66, 1970.

TEDESCO, M.J.; GIANELLO, C.; BISSANI, C.A. \& BOHNEN, H. Análise de solo, plantas e outros materiais. 2.ed. Porto Alegre, Universidade Federal do Rio Grande do Sul, 1995. 147p. (Boletim Técnico, 5)

TISDALE, S.L.; NELSON W.L. \& BEATON, J.D. Soil fertility and fertilizers. 4.ed. New York, Macmillan Publishing Company, 1985. p.351-307.

VIDIGAL, S.M.; PEREIRA, P.R.G. \& PACHECO, D.D. Nutrição mineral e adubação da cebola. Inf. Agropec., 23:36-50, 2002 .

WERNER, H.; BOFF, P.; GONSALVES, P.A.S. \& BEBARBA, J.F. Registro sobre deficiência de zinco em canteiros de mudas de cebola no Alto Vale do Itajaí. In: REUNIÃO DE PESQUISA DA CEBOLA NO MERCOSUL, Ituporanga, Epagri, 1996. p.58. 